Case report

\title{
Adenomatoid hyperplasia of the palate mimicking clinically as a salivary gland tumor
}

\author{
Tetsuo Shimoyama, Masaki Wakabayashi, Takao Kato, Takahiro Kaneko, Norio Horie \\ and Fumio Ide
}

Department of Oral Surgery, Saitama Medical Center, Saitama Medical School, Saitama 350-8550

(Received 24 August 2000 and accepted 12 March 2001)

\begin{abstract}
This report describes an illustrative case of adenomatoid hyperplasia (AH) of the minor salivary glands on the palate of a 31-year-old man. The clinical features of the present lesion corresponded with those of pleomorphic adenoma, but histologically large lobules of normal-appearing mucous acini were found. The cell proliferative activity demonstrated in histological sections, by an immunohistochemical staining of proliferating cell nuclear antigen and Ki-67, showed no statistically significant differences among $\mathrm{AH}$ and a matched control group of normal palatal salivary glands. This case suggests that $\mathrm{AH}$ apparently exhibits an idiopathic, focal hypertrophic lesion of intraoral mucous glands with limited growth potential. (J. Oral Sci. 43, 135-138, 2001)
\end{abstract}

Key words: adenomatoid hyperplasia; minor salivary gland; oral cavity; proliferation marker; tumor-like lesion.

\section{Introduction}

Adenomatoid hyperplasia (AH) of the minor salivary glands is an uncommon clinicopathologic entity usually affecting the palate and mimicking a benign or malignant tumor of salivary gland origin $(1,2)$. It is a non-inflammatory and non-neoplastic focal enlargement of uncertain etiology of the intraoral mucous glands. Until 1999, 97 cases of AH had been reported in the English and Japanese literature

Correspondence to Dr. Norio Horie, Department of Oral Surgery, Saitama Medical Center, Saitama Medical School, 1981 Kamoda, Kawagoe, Saitama 350-8550, Japan.

Tel: +81-492-28-3687 Fax: +81-492-26-5274
(3-24), where three large series were reported $(5,10,14)$. This lesion has attracted a great interest in the dental journals but has received only scant attention in the medical literature (25). In fact, the World Health Organization Classification of Salivary Gland Tumours did not include $\mathrm{AH}$ in a list of tumor-like lesions (26). To our knowledge, only three case reports have appeared in otolaryngologic journals $(8,15,23)$.

The aim of this paper was to present an additional case of AH which demonstrate the typical clinicopathologic characteristics in a 31-year-old man. Further, an attempt was made to analyze the proliferative activity of AH by immunohistochemistry.

\section{Clinical Summary}

A 31-year-old Japanese man was referred for evaluation of a painless mass on the palate. He reported that he had first noticed the small swelling approximately 3 months before. There was no history of trauma or inflammation at this site. The tumor, which was on the left central palate, was relatively soft, well-circumscribed, hemispheric in shape and $12 \mathrm{~mm}$ in maximum diameter (Fig. 1). The covering mucosa was intact and normal in color. Physical examination, other than the palatal mass and laboratory findings, was unremarkable. Prior to the surgical excision, scintigraphy and MRI were obtained that showed no evidence of malignant disease. A preliminary clinical diagnosis of a pleomorphic adenoma was made and the lesion was excised, under general anesthesia. Uneventful healing was observed and there have been no signs of recurrence 2 years after excision.

\section{Pathological Findings}

The lesion was composed entirely of multiple clusters 


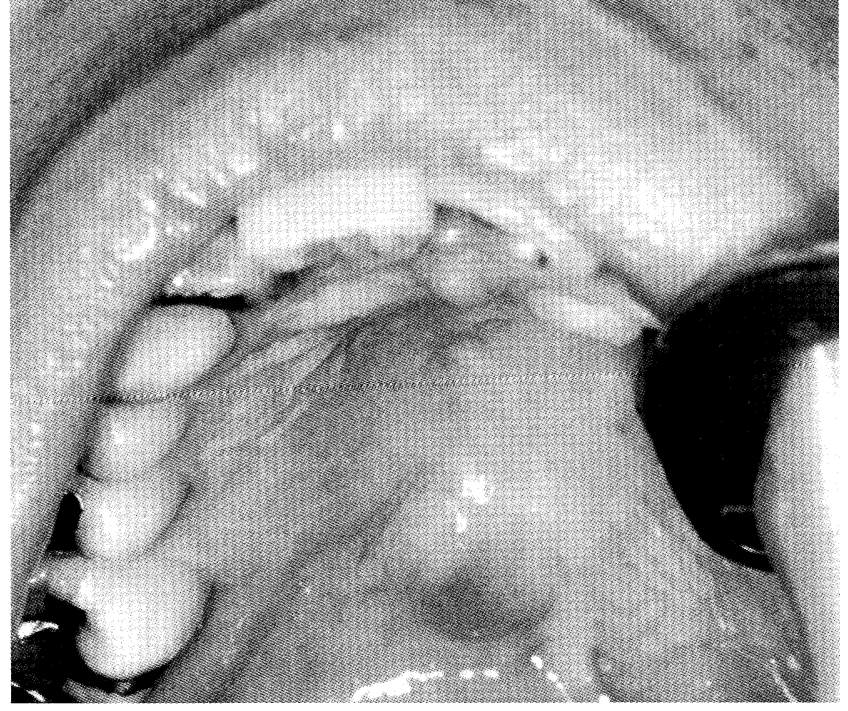

Fig. 1 Clinical aspect of the palatal mass.

of normal-appearing mucous acini surrounded by fibrofatty tissue (Fig. 2). Acini appeared to be hypertrophic and filled with excessive mucous (Fig. 3). Focal areas of mucous spillage were observed but there was no inflammatory reaction (Fig. 4). In contrast to the hypertrophic acini, ductal elements were inconspicuous. No areas of fibrosis were evident. The overlying epithelium was intact but acanthotic. Because of the inability to ensure that the entire mass was $\mathrm{AH}$, additional sections were cut; nothing of significance was found.

In order to analyze the cell proliferative activity of $\mathrm{AH}$, immunohistochemical studies including proliferating cell nuclear antigen (PC10, 1:200, Biogenex, CA, USA) and Ki-67 (MiB-1, 1:50, Zymed, CA, USA) were performed by the streptoavidin-biotin-peroxidase complex method. As a matched control group, normal palatal salivary glands obtained from 5 male patients with an age range of 25 to 40 years were used. The numbers of immunopositive nuclei were counted and the percentage was calculated. The labeling index of $\mathrm{AH}$ was $1.6 \%$ with proliferating cell nuclear antigen and $1.7 \%$ with Ki-67, and that of control group was $1.4 \%$ and $1.8 \%$, respectively. No statistically significant differences were obtained using the Student's $t$-test.

\section{Discussion}

Our comprehensive review of the literature uncovered 80 cases of $\mathrm{AH}$ in Caucasians with black and Hispanic populations (3-14,17). Although several authors claimed that this lesion very rarely occurs in Asians $(10,16,22)$, to our knowledge, 17 cases including 13 Japanese patients have been documented in Asian individuals (14-16,18-24). Thus, it is not as rare in Asians as generally believed.

Reviewing these 97 reported cases, 83 lesions (86\%)

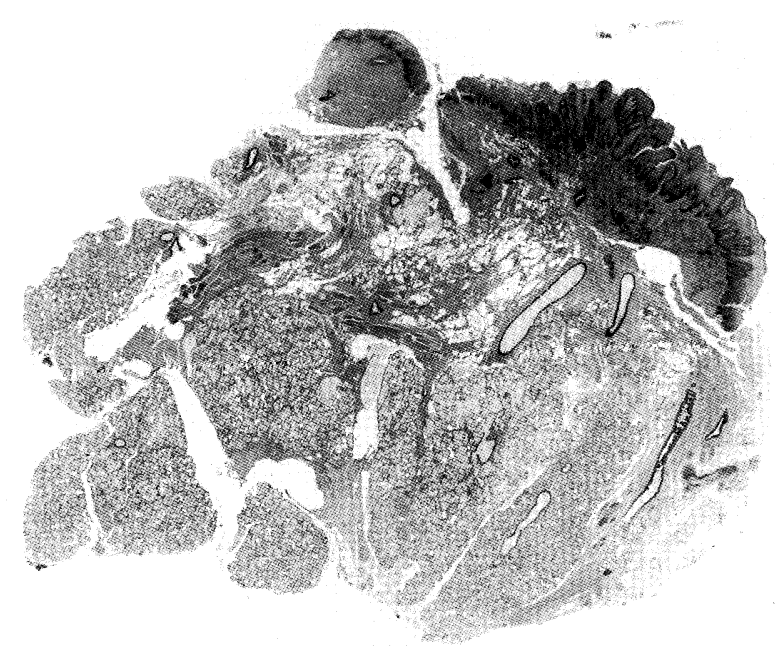

Fig. 2 Palatal lesion with normal overlying epithelium and aggregates of hypertrophic mucous acini surrounded by fibrofatty tissue (HE; original magnification $\times 2.3$ ).

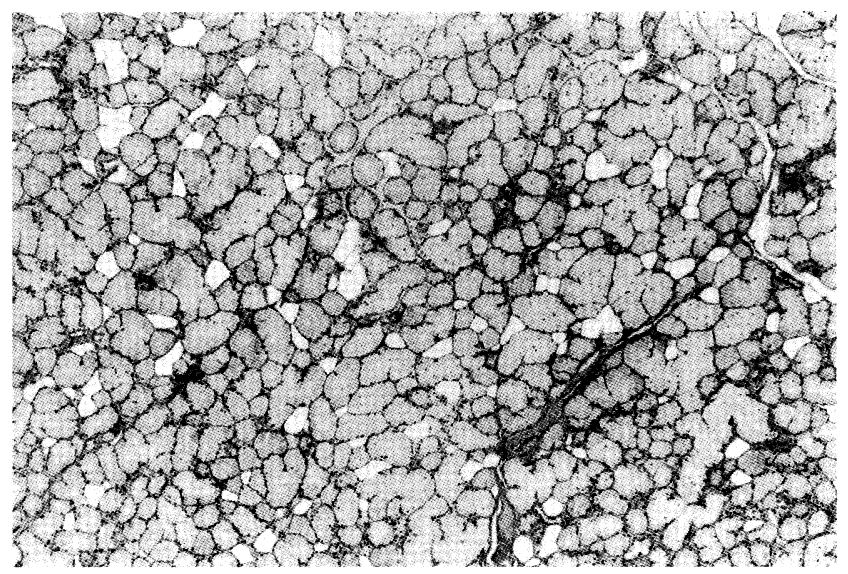

Fig. 3 Normal-appearing mucous acini (HE; original magnification $\times 40$ ).

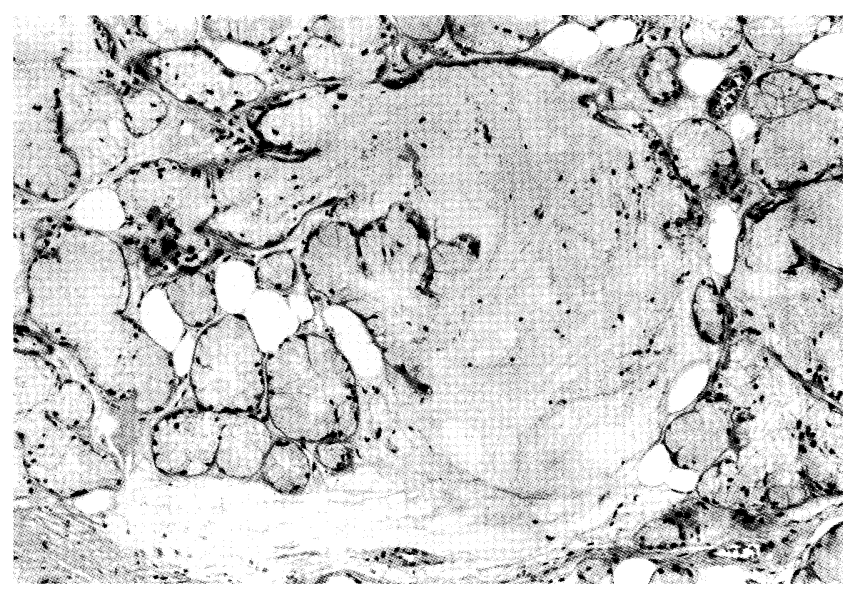

Fig. 4 Focal area of mucous spillage (HE; original magnification $\times 100$ ). 
occurred on the palate. Other oral sites were the mandibular retromolar area ( 7 cases) $(6,7,10,14,16,20)$, tongue (3 cases) $(10,17)$, buccal mucosa ( 2 cases) (10) and lip (2 cases) (10). As has been pointed out previously, this lesion may occur at any site on the oral mucosa where mucous salivary glands normally exist (15). There was a male: female ratio of occurrence of 2:1. Middle-aged patients were more frequently affected; however a wide age range of 9 to 79 years has been reported (10). All lesions presented as a solitary, well-circumscribed asymptomatic tumorlike mass, except for four painful cases $(11,14,16)$ and four multiple lesions (14). Almost all were 10 to $15 \mathrm{~mm}$ in diameter, where the largest size was $40 \mathrm{~mm}$ (13). Since the majority of cases were discovered incidentally, the duration could not be ascertained. With one exception (14), no recurrence has been documented. Therefore, once the diagnosis of $\mathrm{AH}$ has been done in a biopsy, no further treatment is needed.

The significance of AH lies in the clinical resemblance to an intraoral minor salivary gland tumor, but histologically it is easily distinguished from a true neoplastic process $(1,2)$. The bulk of the lesion was composed of multiple clusters of otherwise normal-appearing mucous salivary glands. The acini appeared hypertrophic and filled with mucous. In contrast, ductal structures were inconspicuous throughout the lesion. Focal areas of mucous spillage and fibrosis were sometimes discovered. Chronic inflammation was generally patchy or absent. It is interesting to note that no serous acinar hypertrophy was found in cases of $\mathrm{AH}$ arising from the mixed salivary glands. The overlying epithelium was intact, occasionally exhibiting pseudoepitheliomatous hyperplasia. In the superficial part of the lesion, one case showed features consistent with lichen planus (12) and the other lesion coexisted with pigmented nevus (23).

Analysis of the proliferative activity of $\mathrm{AH}$ has been studied only once in the literature (24). Ohuchi et al. showed that mean number of argyrophilic nuclear organizer regions increased in a stepwise fashion from normal salivary glands to $\mathrm{AH}$ and pleomorphic adenoma (24). In the present study, there were no statistical differences in the labeling indices among $\mathrm{AH}$ and control salivary glands. These results clearly demonstrate that $\mathrm{AH}$ has little or no proliferative activity.

The etiology of AH is uncertain $(1,2)$. No history of drug use or the occurrence of any concomitant disease, which cause enlargement of the salivary glands prior to or at the time of diagnosis, was recorded $(5,10,14)$. Because the palate is the most preferred site of occurrence, chronic local trauma such as dental prosthetic appliances and smoking has been proposed as a likely cause (14). However, only 20 patients with palatal $\mathrm{AH}$ were denture wearers or tobacco smokers $(4,6,12,14,18,21)$. Moreover, this theory is not favored in patients with extrapalatal lesion. In most cases, the nature of AH is idiopathic (10).

Although a variety of salivary gland type tumor and tumor-like lesions may arise from the upper respiratory tract $(25,27)$, we were unable to find reference to a sinonasal $\mathrm{AH}$ by a MEDLINE search. If we compare intraoral AH with those reported in the literature, we find similarities in some respects to seromucinous hamartoma in the nasopharynx (28-31). Whether this type of glandular hamartoma is an upper respiratory analogue to the intraoral $\mathrm{AH}$ is, at present, unclear. We believe that recently reported tumor-like enlargements of the major sublingual glands and $\mathrm{AH}$ are not the same entity, despite their similarities $(32,33)$.

In conclusion, this case is fairly typical of the rare condition of AH. Pathologists and clinicians should be aware of the existence of this type of a minor salivary gland lesion, that is clinically suspected to be a salivary gland tumor, because of therapeutic and prognostic implications.

\section{References}

1. Warnock, G.R., Jensen, J.L. and Kratochvil, F.J. (1991) Developmental diseases. In Surgical pathology of the salivary glands. Ellis, G.L., Auclair, P.L. and Gnepp, D.R. eds., W.B. Saunders Company, Philadelphia, 10-25

2. Ellis, G.L. and Auclair, P.L. (1996) Tumors of the salivary glands.In Atlas of tumor pathology, 3rd series, Fascicle 17. Armed Forces Institute of Pathology, Washington D.C., 411-440

3. Giansanti, J.S., Baker, G.O. and Waldron, C.A. (1971) Intraoral, mucinous, minor salivary gland lesions presenting clinically as tumors. Oral Surg. Oral Med. Oral Pathol. 32, 918-922

4. Devildos, L.R. and Langlois, C.C. (1976) Minor salivary gland lesion presenting clinically as tumor. Oral Surg. Oral Med. Oral Pathol. 41, 657-659

5. Arafat, A., Brannon, R.B. and Ellis, G.L. (1981) Adenomatoid hyperplasia of mucous salivary glands. Oral Surg. Oral Med. Oral Pathol. 52, 51-55

6. Aufdemorte, T.B., Ramzy, I., Holt, G.R., Thomas, J.R. and Duncan, D.L. (1985) Focal adenomatoid hyperplasia of salivary glands. A differential diagnostic problem in fine needle aspiration biopsy. Acta Cytol. 29, 23-28

7. Brannon, R.B., Houston, G.D. and Meader, C.L. (1985) Adenomatoid hyperplasia of mucous salivary glands: a case involving the retromolar area. Oral Surg. Oral Med. Oral Pathol. 60, 188-190

8. Austin, M.B. and Frierson, H.F. Jr. (1986) Pathologic 
quiz case 1 . Minor salivary gland hyperplasia. Arch. Otolaryngol. Head Neck Surg. 112, 336-338

9. Brown, F.H., Houston, G.D., Lubow, R.M. and Sagan, M.A.(1987) Adenomatoid hyperplasia of mucous salivary glands. Report of two cases. J. Periodontol. 58, 125-127

10. Buchner, A., Merrell, P.W., Carpenter, W.M. and Leider, A.S. (1991) Adenomatoid hyperplasia of minor salivary glands. Oral Surg. Oral Med. Oral Pathol. 71, 583-587

11. DeLuke, D.M., Sciubba, J.J., Livanos, G. and Emmings, F.G. (1992) Painful mass of the palate. J. Oral Maxillofac. Surg. 50, 59-61

12. Scully, C., Eveson, J.W. and Richards, A. (1992) Adenomatoid hyperplasia in the palate: another sheep in wolf's clothing. Br. Dent. J. 173, 141-142

13. Petri, W.H.III, Carr, R.F. and Kahn, C.S. (1993) Adenomatoid hyperplasia of the palate. J. Oral Maxillofac. Surg. 51, 310-311

14. Barrett, A.W. and Speight, P.M. (1995) Adenomatoid hyperplasia of oral minor salivary glands. Oral Surg. Oral Med. Oral Pathol. Oral Radiol. Endod. 79, 482-487

15. Bryant, C., Manisali, M. and Barrett, A.W. (1996) Adenomatoid hyperplasia of palatal minor salivary glands. J. Laryngol. Otol. 110, 167-169

16. Chen, Y.K., Lin, C.C., Lin, L.M. and Yan, Y.H. (1999) Adenomatoid hyperplasia in the mandibular retromolar area. Case report. Aust. Dent. J. 44, 135136

17. Carlos, R., Aguirre, J.M. and Pineda, V. (1999) Asymptomatic posterolateral lingual mass. Oral Surg. Oral Med. Oral Pathol. Oral Radiol. Endod. $88,654-656$

18. Ishibashi, T., Takasaka, E., Takeda, S. and Nemoto, K. (1986) Palatine gland hyperplasia presenting clinically as tumor: report of a case. Nippon Koku Geka Gakkai Zasshi 32, 1042-1045 (in Japanese)

19. Ono, Y., Tsushima, T. and Kaimori, M. (1992) Palatine gland hyperplasia presenting clinically as pleomorphic adenoma: report of a case. Nippon Koku Geka Gakkai Zasshi 38, 496-497 (in Japanese)

20. Sakashita, H., Miyata, M., Miyamoto, H., Miyaji, Y. and Kurumaya, H. (1994) Adenomatoid hyperplasia of minor salivary gland: a case involving the retromolar area. Nippon Koku Kagakkai Zasshi 43, 591-594 (in Japanese)

21. Hamada, Y., Hamada, A., Takada, N., Horiuchi, T., Matsumoto, Y. and Seto, K. (1995) A case of minor salivary gland hyperplasia located on the soft palate. Nippon Koku Geka Gakkai Zasshi 41, 838-840 (in
Japanese)

22. Nozaki, S., Araki. A., Nakagawa, K. and Yamamoto, E. (1996) Adenomatoid hyperplasia of the palate in an Asian child. J. Oral Maxillofac. Surg. 54, 627628

23. Harada, H., Morimatsu, M., Kusukawa, J. and Kameyama, T. (1997) A hamartoma-like mass on the palate? A possible discussion regarding the components of a pigmented naevus and hyperplastic salivary gland. J. Laryngol. Otol. 111, 296-299

24. Ohuchi, T., Abiko, Y., Saitoh, M., Kuraguchi, J., Nishimura, M., Arai, J., Ogawa, M., Satoh, M., Kohama, G. and Kaku, T. (1997) Adenomatoid hyperplasia of minor salivary glands: analysis of proliferative activity and a review of the literature. Nippon Koku Geka Gakkai Zasshi 43, 541-548 (in Japanese)

25. Shanmugaratnam, K. (1991) Histological typing of tumours of the upper respiratory tract and ear. 2nd ed., Springer-Verlag, Berlin, 84

26. Seifert, G. (1991) Histological typing of salivary gland tumours. 2nd ed., Springer-Verlag, Berlin, 34-38

27. Heffner, D.K. (1991) Sinonasal and laryngeal salivary gland lesions. In Surgical pathology of the salivary glands. Ellis, G.L., Auclair, P.L. and Gnepp, D.R. eds., W.B. Saunders Company, Philadelphia, 544-559

28. Baillie, E.E. and Batsakis, J.G. (1974) Glandular (seromucinous) hamartoma of the nasopharynx. Oral Surg. Oral Med. Oral Pathol. 38, 760-762

29. Zarbo, R.J. and McClatchey, K.D. (1983) Nasopharyngeal hamartoma: report of a case and review of the literature. Laryngoscope 93, 494-497

30. Graeme-Cook, F. and Pilch, B.Z. (1992) Hamartomas of the nose and nasopharynx. Head Neck 14, 321-327

31. Wenig, B.M. and Heffner, D.K. (1995) Respiratory epithelial adenomatoid hamartomas of the sinonasal tract and nasopharynx: a clinicopathologic study of 31 cases. Ann. Otol. Rhinol. Laryngol. 104, 639645

32. Campos, L.A. (1996) Hyperplasia of the sublingual glands in adult patients. Oral Surg. Oral Med. Oral Pathol. Oral Radiol. Endod. 81, 584-585

33. Tagawa, S., Inui, M., Mori, A., Seki, Y., Murata, T. and Tagawa, T. (1996) Adenomatoid serous hyperplasia of sublingual gland: a case report. Oral Surg. Oral Med. Oral Pathol. Oral Radiol. Endod. $82,437-440$ 